\title{
Aproximación a la nueva narrativa catalana ${ }^{1}$
}

\author{
FIDEL ALONSO GONZÁLEZ \\ (Liceo Español de París)
}

Dentro de las posibilidades de la obra literaria en cuanto objeto susceptible de sistematización y de análisis de acuerdo con un método científico, existen unas constantes, admitidas por los investigadores, en torno a las cuales se mueve el sistema literario:

- Los procesos de renovación, constituidos por generaciones, grupos, movimientos y tendencias.

- La búsqueda de un lenguaje y estilo de expresión.

- La tensión entre tradición y modernidad.

- La tensión entre centro y periferia: Literatura popular, culta y transgresora.

- Los lazos con la economía y el mercado.

- La búsqueda de legitimación o afirmación.

- La crítica, la academia, la historia —la razón analítica一, como discurso de orden.

Teniendo en cuenta estos postulados, vamos a acercarnos a un fenómeno literario único y de gran interés desde distintos puntos de vista: la recuperación de la narrativa en lengua catalana tras el franquismo. Nos referimos con este concepto tanto a la novela como al cuento o narrativa breve, dos campos, estos últimos, que vamos a integrar siguiendo un criterio práctico.

Nuestro punto de partida es considerar el fenómeno a la luz de unas constantes históricas y literarias que definen la narrativa en castellano del mismo periodo, cuyo alcance e implantación va mucho más allá de las tres comunidades autónomas en las que dicha lengua es cooficial: Cataluña, País Valenciano y Baleares. No hay que olvidar tampoco, pese al claro protagonismo de Cataluña - linguístico y editorial antes que literario - , las peculiaridades de los otros dos territorios, más marcadas en el caso del País Valenciano.

${ }^{1}$ Este trabajo cuenta con unos apéndices informativos que se pueden consultar en la página web del autor: http://www.alonso-gonzalez.net/otras_literaturas/index.htm. 
Veremos, pues, en primer lugar, si existe una verdadera legitimación —entendida como reconocimiento y aceptación - de esta literatura en el contexto general del Estado español, a partir fundamentalmente de la tarea que realiza la crítica especializada en todo este periodo, una crítica que surge siempre dentro del subsistema literario catalán, uniformizante y polarizada en Cataluña.

Comprobaremos, en segundo lugar, si el mercado y la industria editorial adquieren en la producción novelística catalana la misma importancia que en la llamada «nueva narrativa» en castellano y qué función tiene en ello la boyante infraestructura editorial y comercial en torno a Barcelona.

Por último, los aspectos puramente literarios nos deben ayudar a caracterizar y sistematizar el género y periodo abordados: Qué grupos y movimientos dentro de la evolución, qué estilo y lenguaje característicos, qué postura ante la tradición literaria (entre renovación y ruptura) y qué actitud ante la obra narrativa como objeto artístico: elitista, transgresora, de proyección masiva, etc.

Veremos, al final de nuestro trabajo, si es posible articular una teoría que defina la importancia de la narrativa catalana de las últimas décadas y señalar su lugar con respecto a la narrativa en castellano.

\section{EL RENACER DE LOS 60, ÉPOCA DE TRANSICIÓN Y DE CONFLUENCIA GENERACIONAL}

Si en castellano la renovación narrativa de los años 60 se inicia en 1962 con Tiempo de silencio, de Luis Martín Santos, en catalán será Terenci Moix (Barcelona, 1942) el autor del cambio, con dos novelas de 1969: El dia que va morir Marilyn y Onades sobre una roca deserta. Pero Moix, además de anticiparse al periodo siguiente, representa con estos sus primeros títulos la culminación de una década clave para la narrativa catalana, que supone la transición entre la posguerra y el definitivo resurgir de los años 70 .

La década se había iniciado ya con dos importantes novelas, dos títulos de referencia en la literatura catalana contemporánea: Bearn o la sala de les nines (1961), del mallorquín Llorenç Villalonga, nacido en 1897, y La plaça del Diamant, de Mercè Rodoreda, nacida en Barcelona en 1908.

Otros novelistas clave de generaciones anteriores se consolidan también en esta década, como es el caso de Manuel de Pedrolo (1918), Maria Aurèlia Capmany (1918) o Joan Perucho (1920).

Simultáneamente, los años 60 representan para la literatura catalana - también con retraso respecto a la literatura en castellano- el desarrollo del llamado realismo social en narrativa, con autores como Estanislau Torres (1926), Ramon Folch y Camarasa (1926), Josep M. Espinàs (1927), Víctor Mora (1931) y Joaquim Carbó (1932).

Por otra parte, un segundo grupo de autores exiliados regresan durante la década —otros lo habían hecho ya en los años 40-, gracias a la incipiente apertura política que se produce y al creciente espacio y reconocimiento obtenidos 
por las letras catalanas: Vicenç Riera Llorca (1903), Pere Calders (1912), Avel-lí Artís-Gener (1912), etc.

Hasta aquí hemos citado autores, a excepción de Villalonga, nacidos todos ellos en Cataluña, pero éste es el periodo en que se produce también un temprano resurgimiento de la narrativa en las Islas Baleares, con nombres tan destacados como Blai Bonet (1926), Baltasar Porcel (1937) y Gabriel Janer Manila (1940), además del citado Llorenç Villalonga.

Hay que tener en cuenta como factor decisivo en este resurgir de la novela catalana en los años 60 -nos referimos a la novela en catalán--, paralelo al proceso político, cultural y linguístico favorable, la creación de una infraestructura editorial sólida, con el nacimiento, a principios de la década, de Ediciones 62. También los premios, como resorte y aliciente económico: En 1960 se crea el más emblemático hasta la actualidad, el premio Sant Jordi de novela (a partir del premio Joanot Martorell, que existía desde 1948, el cual había sucedido a su vez al premio Crexells, el más antiguo de las letras catalanas, existente desde 1928). En tercer lugar debe destacarse la fundación, en 1961, de Omnium Cultural, entidad destinada a la promoción y la normalización del catalán, que cuenta con 16.000 socios en la actualidad.

Comienza, pues, en los 60 , un proceso de avance y crecimiento en la narrativa catalana que no cesará hasta la actualidad. En palabras de Àlex Broch, «La literatura catalana entre 1960 i ara mateix ens situa en la complexitat $i$ dinamisme d'un marc que recull les tensions, els debats i les transformacions d'una cultura escindida entre la lluita pel reconeixement social de la seva personalitat $i$ un esforç per assolir la modernitat literària. [...] És així que la dècada dels seixanta esdevingué de cabdal importància en el ressorgiment de les lletres catalanes. Foren anys d'il.lusió i d'intensitat, i una cruilla en el temps on es trobaren, en estadis diferents de contigüitat, els escriptors marcats per l'experiència de la Guerra Civil Espanyola i una nova generació que, a partir dels anys setanta, encarnà els valors de la renovació $i$ el canvi en el marc de la literatura catalana contemporània.» ${ }^{2}$

\section{LA GENERACIÓ LITERÀRIA DELS 70}

En 1971, Guillem-Jordi Graells y Oriol Pi de Cabanyes publican el libro $L a$ Generació Literària dels $70,{ }^{3}$ que, por razones de censura, no sería distribuido hasta 1976. Dicho libro está integrado por 25 entrevistas procedentes de un cuestionario enviado a otros tantos escritores con obra publicada, nacidos entre 1939 y 1949 (ambos años incluidos), cuyas preguntas se refieren a aspectos tanto literarios como sociológicos. Diez de esos autores son narradores, ocho de

2 Àlex Broch y otros: Panorama de la Literatura Catalana, Departament de Cultura, Generalitat de Catalunya, Barcelona, 1997, pp. 37-38.

${ }^{3}$ Edit. Pórtico, Barcelona, 1971. Resulta interesante también el n.. 6 de la revista Quaderns Divulgatius, editada por la Associació d'Escriptors en Llengua Catalana, de septiembre de 1996, número monográfico que, con el título de «La generació dels setanta: 25 anys», hace un balance por géneros literarios, a 25 años vista, del libro de Graells y Pi de Cabanyes. 
ellos figuras que se han consolidado con posterioridad: los barceloneses Robert Saladrigas, Terenci Moix, Jaume Fuster, Montserrat Roig, y Jordi Coca y los mallorquines Gabriel Janer i Manila, Guillem Frontera y Maria Antònia Oliver.

Éstas son las conclusiones a las que llegan los autores del libro en cuanto a los rasgos comunes a los entrevistados, que constituyen el criterio para considerarlos como generación literaria:

1) Todos han vivido la inmediata posguerra, son antidogmáticos, separan el arte de la política y tienen sensación de impotencia ante la realidad que les rodea.

2) Están profundamente marcados por los medios de comunicación (en especial cine, TV y cómic), que han mitificado, y tienen un claro afán cosmopolita. Se trata por otra parte de una generación contradictoria, con una crisis ideológica que les impulsa a eliminar tabúes infantiles y a desmitificar los valores tradicionalmente aceptados.

3) Viven el «boom» editorial de los 60: premios, revistas, triunfo fácil para los jóvenes escritores.

4) Envueltos por la sociedad de consumo, reniegan de ella, pero saben que no pueden escapar. Proponen, por el contrario, la necesidad de afianzamiento del individuo.

5) Todos son autodidactas. Muchos empiezan, dadas las circunstancias, escribiendo en castellano, tras darse cuenta de la artificiosidad y el escaso eco de la lengua propia.

6) Los narradores poseen una conciencia absoluta de la crisis de la novela como género y buscan nuevas formas expresivas y nuevas estructuras narrativas. Se percibe la influencia de la novela norteamericana de entreguerras y, en menor medida, de autores italianos e hispanoamericanos. Muestran un desigual y precario conocimiento de la novelística en catalán.

7) Pobreza de lenguaje generalizada: presión estándar de los medios de comunicación y de la artificiosidad de Espriu en el otro extremo. Cada autor tiene preocupaciones lingüísticas de investigación, de creación de un estilo propio. Los mallorquines muestran una mayor riqueza y expresividad (léxico dialectal y coloquialidad), frente a una lengua popular, defectuosa y llena de barbarismos de los autores barceloneses. Se protesta contra la dictadura de los correctores. Hay unanimidad absoluta con respecto al bilingüismo pero los autores ven clara la ventaja del castellano en cuanto a difusión (aceptando la importancia del catalán desde el punto de vista creativo).

8) Deseo de una cierta profesionalización y opiniones variables sobre la sindicación y el apoyo a la cultura catalana.

9) La mayoría de estos escritores viven en Barcelona, aunque no han nacido allí, aprovechando el contacto con la Universidad y con el mundo de la edición, pero se oponen al centralismo barcelonés. 
10) Otra nota característica común a los autores entrevistados es la irreligiosidad.

Efectivamente, a lo largo de la década resultó premonitorio y acertado el libro, que había presentado sólo las figuras iniciales de una nueva generación literaria. A los nombres citados deben añadirse en primer lugar los de autores valencianos que constituyen una verdadera eclosión narrativa en dicho territorio a partir de mediados de la década: Amadeu Fabregat, Joan Francesc Mira, Isa Tròlec (Joan B. Menguall), Josep Piera, Ferran Cremades, J. Gandia Cassimiro, Josep Lluís Seguí, Isabel-Clara Simó, Biel Mesquida y Ferran Torrent.

La nómina generacional se completa, entre otros, con Antònia Vicens, Carme Riera, Valentí Puig y Pau Janer, autores nacidos en territorio balear; un autor nacido en Mequinensa (Zaragoza), Jesús Moncada; y los siguientes autores oriundos de Cataluña (barceloneses en su mayor parte): Quim Soler, Ignasi Riera, Joan Rendé, Pep Albanell, Isidre Grau, Jaume Cabré, Maria Barbal, Oriol Pi de Cabanyes, Ramon Solsona, Quim Monzó, Margarida Arizteta, Miquel de Palol y Lluís Maria Todó.

Desde el punto de vista del contenido, Francesc Calafat ${ }^{4}$ establece para los autores de este periodo la siguiente clasificación, que coincide, en parte, con la territorialidad:

- Crónica de una educación sentimental, que narra la relación del individuo con su entorno, posterior confrontación y proyección utópica que desembocará en la asumpción de la imposibilidad del cambio social: T. Moix, M. Roig, F. J. Mira, Janer i Manila y G. Frontera, entre otros.

- Los autores mallorquines se decantan por novelar linajes familiares y microestructuras espaciales globalizadoras de geografías más amplias, a las que aluden metafóricamente, como también por la incorporación de elementos mágicos y maravillosos.

- Otros novelistas más radicales, entre ellos los valencianos, trasladan la heterodoxia vital a unas páginas en las que desaparece la tensión del personaje con el entorno para convertirse en rechazo frontal de la sociedad establecida:

- La novela como espacio para todas las transgresiones.

- Se rompen las fronteras entre géneros, con tendencia al texto poemático.

- Discurso confuso, que avanza en espiral, pensamiento en suspensión.

- Voluntad barroca de deformación de la representación.

- La teatralidad y la recreación de la gestualización.

Àlex Broch, por su parte, diferencia dos periodos en la década, hasta 1975 (eclosión) y desde esa fecha hasta 1980 (transición), y hace la siguiente clasificación de obras y autores a partir de 1974, teniendo en cuenta tanto el aspecto

${ }^{4}$ F. Calafat: «Tribulacions d'una literatura en expansió», en Àlex Broch y otros, 70-80-90- $\mathrm{Li}$ teratura (Dues dècades des de la tercera i última), Quaderns 3 i 4, Valencia, 1992, pp. 63 y siguientes. 
ideológico como el experimentalismo formal, que serían dos caras de la misma moneda: ${ }^{5}$

a) Dentro de los límites (práctica transformadora).

- Enlace con la vanguardia histórica: A. Munné-Jordà con Proses del pintor (1978).

- Destruir la jerarquía y el poder del autor: Carles Reig con Contraataquen (1977).

- La modernidad temática: Quim Monzó con Self-Service (1977) y Uf, va dir ell (1978).

b) En los límites (práctica transformadora y transgresora).

- Realidad o ficción, cuestionar la misma literatura: J. Gandia Cassimiro con Dentadura Postissa (1975).

- Teorizar la modernidad: Oriol Pi de Cabanyes con Esquinçalls d'una bandera (1977).

- Intensificación de las estructuras narrativas: Amadeu Fabregat con Assaig d'aproximació a «Falles folles fetes foc» (1974).

- Sensualidad y libertad de palabra: Ferran Cremades con Coll de serps (1978) y Josep-Lluís Seguí con Espai d'un ritual (1978).

c) Cruzar los límites (práctica transgresora).

- La primera intertextualidad: Biel Mesquida con L'adolescent de sal (1975).

- Transgresión ideológica —homosexualidad y pornografía-: Lluís Fernández con L'anarquista nu (1979).

- En busca del referente: Jordi Coca con Iadwiga (1978), Carles H. Mor con Desig/enuig y A. Munné-Jordà con $F-a$ les memòries del doctor Oleguer Verdós- (1978).

- Una destrucción casi total; en el difícil límite del nacionalismo: Biel Mesquida con Self-Service (1977) y Puta Marès -ahí-(1978).

El criterio de Broch, basado en la tendencia transformadora o transgresora en los límites de los sistemas lingüístico y literario, es coherente con la polémica surgida en la prensa catalana a mediados de la década entre dos colectivos de escritores: «Trencavel» (renovadores, que posteriormente formarán «Ofelia Dracs») ${ }^{6} \mathrm{e}$ «Ignasi Ubac» (transgresores, más tarde en torno a la revista Taula de Canvi, caen en la marginalidad en los años 80).

${ }^{5}$ A. BROCH: Literatura catalana dels anys setanta, Ediciones 62, Barcelona, 1980, pp. 112-114.

6 En un momento u otro, el colectivo «Ofelia Dracs» estuvo integrado por los siguientes autores: Josep Albanell, Margarida Aritzeta, Jaume Cabré, Assumpció Cantalozella, Joaquim Carbó, Miquel Desclot, Joana Escobedo, Jaume Fuster, Isidre Grau, Josep M. Illa, Quim Monzó, MariaAntònia Oliver, Carles Reig, Joan Rendé, Xavier Romeu, Josep-Lluís Seguí, Antoni Serra, Joaquim Soler, Roser Vernet y Vicenç Villatoro. Dicho colectivo se dedicó, con suerte desigual, ya en la década de los 80 , a la práctica y reivindicación sistemática de diferentes géneros: novela erótica, fantástica, negra, de ciencia-ficción, etc. 
Textualismo, heterodoxia lingüística, humor y erotismo como rebeldía y autoafirmación, ruptura de géneros, omnipresencia de los mass media, abandono de los cánones dogmáticos y realistas de la novela de posguerra. Son los «novísimos» de la literatura catalana - serviría la misma etiqueta que consagró Castellet en su antología de 1970 para la poesía en castellano-. Se trata, en definitiva, del periodo en que florece en toda su plenitud la narrativa en catalán, enriquecida por las aportaciones y peculiaridades de sus tres territorios con claros rasgos distintivos pero que afirman y enriquecen el conjunto. Prueba de ello será la creación, en 1977, de la Associació d'Escriptors en Llengua Catalana (AELC), que cuenta en la actualidad con más de 900 integrantes.

\section{AÑOS 80: LA NOVELA DE GÉNERO Y EL AUGE EDITORIAL}

Nacidos en su mayoría entre 1955 y 1965, un nutrido grupo de escritores se dan a conocer en la década de los 80 . Entre ellos, A. Broch ${ }^{7}$ destaca los siguientes: los mallorquines Gabriel Galmés y Maria de la Pau Janer; los autores del País Valencià Joan M. Monjo, Manuel Joan i Arinyó, Maria Jaén, Josep Franco y Vicent Josep Escartí; los barceloneses (capital y provincia) Carles Decors, Jordi Viader, Pilar Rahola, Alfred Bosch, Josep Bras, Toni Pascual, Vicenç Villatoro, Isabel Olesti, Lluís-Anton Baulenas, Òscar Pàmies y Màrius Serra; los nacidos en Gerona (capital y provincia) J. N. Santaeulàlia, Sílvia Manzana, Maria Mercè Roca, Josep Maria Fonalleras y Vicenç Pagès; y los autores de origen francés Sergi Pàmies y Joan-Lluís Lluís.

La nueva generación de escritores constituye una alternativa dinámica al grupo de los 70, contra el que manifiestan una clara actitud crítica. Dos antologías, aparecidas en 1989, sirven para consolidar la presencia de los jóvenes narradores: se trata de La Profecia, a cargo de Carles Geli y Jaume Subirana, y Farenheit 212 , de Joan Orja, en la cual, además de presentar una nueva generación, se cuestiona la vigencia de los postulados y de los autores pertenecientes a la Generación de los 70 .

En la década de los 80 y coincidiendo con un mercado editorial en auge que requiere productos de fácil comercialización, las inquietudes textuales y experimentalistas van dejando sitio a la narratividad, la complicidad con el lector, la revalorización de la intriga y la vuelta a la novela de género. Se trata de un fenómeno que corre paralelo a lo que sucede en la literatura en castellano y que se irá incrementando a lo largo de la década.

Prolifera así la novela de tema histórico, de intriga y de aventuras, con autores como Lluís Racionero (Leida, 1940), Jaume Cabré (Barcelona, 1947), Ferran Cremades (Valencia, 1950) y el más destacado, Ferran Torrent (Valencia, 1951), autores del periodo anterior que desarrollan ahora su producción más significativa.

7 Àlex Broch: Panorama de la literatura catalana, op. cit., p. 61, y Àlex Broch, Literatura catalana dels anys vuitanta, Ediciones 62, Barcelona, 1991, p. 48. 
El marco histórico que aparece en la obra de estos autores va perdiendo su contenido ideológico y reflexivo para quedarse en materia de recreación literaria. Es el caso de autores como Josep Franco y Vicent Josep Escartí, ya citados en la nueva promoción. Otros, como el veterano Joan Perucho o Jaume Fuster (de la etapa anterior), cultivan la novela de aventuras entre lo mítico y lo fantástico.

En la segunda mitad de la década tendrá éxito la línea iniciada por Quim Monzó: narrar irónicamente la vida masificada actual. Se desarrolla una narrativa de voluntad realista que la crítica ha etiquetado como «costumbrismo urbano», en la que destacan Toni Cucarella (Valencia, 1959), Rafael Vallbona (Barcelona, 1960) y Màrius Serra (Barcelona, 1963). Otros autores realizan una interpretación alegórica o metafórica de este mundo, son los ya citados de la última generación, S. Pàmies, J. M. Fonalleras, I. Olesti y V. Pagés, junto con el valenciano Tomàs Belaire.

También se desarrolla una narrativa basada en el mundo rural, con autores ya maduros como los mallorquines M. Àngel Riera, Baltasar Porcel y Antoni Serra y el barcelonés Emilio Teixidor, junto con nombres más recientes como Jesús Moncada o Maria Barbal. ${ }^{8}$

Un aspecto importante en esta reorientación narrativa de los 80 es el resurgir del cuento, género ampliamente cultivado por buena parte de los autores citados y que la crítica valora tanto por su cantidad como por su calidad. Cabría destacar en este campo la obra peculiar de un autor cuya producción se centra en la narrativa breve: Rafael Gomar (Gandia, 1955).

Y un último matiz: nueva sensibilidad lingüística, con la incorporación de todos los registros y sobre todo de un catalán estándar normalizado y válido para los diferentes territorios, en el que el criterio funcional de las editoriales ha servido para igualar diferencias dialectales. En este proceso continuado de normalización linguística y literaria, debe destacarse la creación, en 1987, de la Institució de les Lletres Catalanes, adscrita al Departamento de Cultura de la Generalitat, órgano del Gobierno dedicado específicamente a la promoción de la literatura catalana.

\subsection{Mientras tanto, en castellano: aparición de la nueva narrativa española}

En octubre de 1972, los editores, Carlos Barral y José Manuel Lara, asociados para la ocasión, presentaron, bajo el eslogan « ¿Existe o no una nueva novela española?», el lanzamiento de una colección de obras de 17 autores, 10 de ellos denominados «novísimos» (algunos pertenecían a la promoción de poetas así llamada por Castellet en su antología de 1970) y 7 de generaciones anteriores. Eran los primeros Vázquez Montalbán, Vaz de Soto, López Pereira, J.A. Gabriel y Galán, Ramón Hernández, Félix de Azúa, Ana María Moix, Javier del Amo, Javier Fernández y Carlos Trías, y los segundos G. Sánchez Espeso, García Hor-

8 Véase el estudio de F. CALAFAT: «Tribulacions d'una literatura en expansió», en Àlex Broch y otros, 70-80-90-Literatura (Dues dècades des de la tercera i última), op. cit., pp. 69-83. 
telano, Baltasar Porcel, Ramón Carnicer, Antonio Ferres, Concha Alós y M. ${ }^{a}$ Luz Melcón. La iniciativa no obtuvo en absoluto el éxito editorial esperado —es decir, «no» debía de existir «aún» una nueva novela española--, pero algunos de esos autores, así como los editores que llevan a cabo la iniciativa, serán figuras destacadas de la nueva narrativa española, cuando ésta se inicie pocos años más tarde. ${ }^{9}$

La crítica coincide de manera prácticamente unánime en reconocer la existencia de un grupo generacional que inicia su producción narrativa tras la muerte de Franco y se diferencia claramente de los movimientos anteriores en la literatura española posterior a la guerra civil: realismo existencial de la posguerra, realismo social de los años 50 y experimentalismo y neovanguardia a partir de los 60 . Han querido ver los críticos en estos autores un nuevo y original tratamiento de la realidad, ironía, ausencia de compromiso político, «reencuentro con el lector», «vuelta a la narratividad», etc; y sobre todo, un elevado nivel de calidad (a pesar de la cantidad), que explica en buena medida la aceptación y demanda que estos autores han tenido por parte de los lectores nacionales y extranjeros. ${ }^{10}$ Pasará una década desde su inicio para que el movimiento llegue a su plenitud (el tiempo necesario para que el cambio político dé sus frutos culturales) y aún hoy no se ha estudiado a fondo ni sistematizado esta brillante producción narrativa en la literatura española - -salvo algunos tímidos acercamientos de enfoque histórico o sociológico-. ${ }^{11}$ Ya puede observarse, sin embargo, con cierta perspectiva, teniendo en cuenta que, a partir de 1995 aproximadamente, la corriente deja paso a nuevas hornadas de autores jóvenes, entre los que destaca el controvertido grupo que se ha consolidado con el nombre de «realismo sucio», «neorrealismo» o nueva versión de la americana «Generación X».

El verdadero inicio de la nueva narrativa española tiene lugar en la primavera de 1975 - año clave para la historia de España - con la publicación por Seix-Barral de la novela La verdad sobre el caso Savolta, de Eduardo Mendoza (Barcelona, 1939), obra que representa, con una visión irónica y desencantada, la vuelta -desde la experimentación de la década anterior- a formas narrativas tradicionales: novela policiaca y de aventuras, con ingredientes de folletín y de novela rosa, todo ello centrado en un marco histórico próximo y concreto. Fue tal el éxito de crítica y de público que alcanzó dicha obra que en otoño aparecía ya la primera reimpresión.

Un año antes y en una editorial más modesta, Ediciones El Espejo, había publicado Juan José Millás (Valencia, 1946) su primera novela, Cerbero son las sombras, premio Sésamo 1975. En 1977, Alfaguara lanzará la segunda obra de

${ }^{4}$ JoSÉ M. ${ }^{\wedge}$ Martínez CACHero narra minuciosamente el proceso y el resultado de este peculiar lanzamiento editorial en su libro La novela española entre 1936 y el fin de siglo, Castalia, Madrid, 1997, pp. 316-327.

10 Pueden consultarse al respecto, en el número extraordinario de la revista Insula (589-590, enero-febrero 1996), titulado El espejo fragmentado. Narrativa española al filo del milenio, artículos de Santos Sanz Villanueva, Ramón Acín, Luis Miguel Fernández, J. Antonio Fortes, Jordi Gracia, Gonzalo Navajas y Juan Oleza.

1 Tal es el caso de la obra de Fátima Serra, La nueva narrativa española. Tiempo de tregua entre ficción e historia, Pliegos, Madrid, 2000. 
Millás, Visión del ahogado, considerada como la primera novela de la transición, que consolida definitivamente a su autor. Son estos dos autores, con las obras citadas, quienes representan, según la crítica, el inicio de la nueva narrativa española.

Un editor catalán y dos autores de ese ámbito que optan por el castellano, marcan curiosamente el inicio de la nueva corriente de la literatura española. Se trata de un periodo brillante y prolífico con respecto al género narrativo, que abarca desde la muerte de Franco hasta la vuelta al poder de la derecha en España en 1996, coincidiendo con la transición política, la incorporación de España a las instituciones comunitarias europeas, su proyección internacional con las Olimpiadas y la Expo 92, el éxito de la «movida» madrileña, el triunfo del cine español con Garci y Almodóvar y la concesión del premio Nobel a Cela en 1989.

En esta especie de «boom» literario y comercial con epicentro en Madrid -donde residen buena parte de los autores- están presentes escritores procedentes del ámbito catalanohablante (Vázquez Montalbán, Manuel Vicent, VilaMatas, Félix de Azúa, Rafael Chirbes, Terenci y Ana M. ${ }^{a}$ Moix, Javier García Sánchez, Esther Tusquets y Cristina Fernández Cubas, además de los dos ya citados), gallegos (Manuel Rivas, Marina Mayoral), vascos (Bernardo Atxaga), leoneses (Jose M. ${ }^{a}$ Merino, Luis Mateo Díez, J. Pedro Aparicio, Julio Llamazares), aragoneses (Javier Tomeo, Soledad Puértolas, I. Martínez de Pisón), madrileños (Javier Marías, Lourdes Ortiz, Rosa Montero, Almudena Grandes), andaluces (A. Muñoz Molina, Justo Navarro, Eduardo Mendicutti) y de otras variadas procedencias peninsulares: A. Pérez Reverte (Murcia), Alvaro Pombo y Alejandro Gándara (Santander), Manuel de Lope (Burgos), Eduardo alonso (Asturias), G. Martín Garzo (Valladolid), Luis Landero y Adelaida G. ${ }^{a}$ Morales (Badajoz), Clara Sánchez (Guadalajara), Jesús Ferrero (Zamora) y Miguel Sánchez-Ostiz (Pamplona). ${ }^{12}$

\section{PECULIARIDAD DE LA NARRATIVA CATALANA EN EL PAÍS VALENCIANO}

En las dos primeras décadas de la posguerra, el panorama de la narrativa catalana en el País Valenciano es desolador, con apenas un 5\% del total de los títulos publicados en ese territorio, siendo narrativa costumbrista el $40 \%$ de dichos títulos en catalán. Desde el punto de vista editorial, existía en el País Valenciano una especie de circuito estanco en la relación autor-editor-lector, que no empezará a despegar hasta los años 60 . A esta situación se añade la dificultad para conseguir una lengua literaria que prescinda de los problemas y vacilaciones del valenciano estándar.

12 No se pretende of recer un repertorio exhaustivo de autores. Por otra parte, debe tenerse en cuenta que novelistas de generaciones anteriores se incorporan también a la nueva corriente narrativa, como Cela, Delibes, Torrente Ballester, J. Luis Sampedro, C. Martín Gaite, J. Marsé, Juan y Luis Goytisolo, J. Benet, etc. 
En 1978 se edita la primera novela valenciana en catalán fuera del territorio valenciano; se trata de Coll de serps, de Ferran Cremades, premio Sant Jordi 1977, publicada por la editorial Ucronia. Se supera así el circuito estanco conectando con el circuito catalán en general. A partir de esta década serán mayoría las obras editadas por catalanes, coincidiendo con el aumento de cantidad y de calidad en la narrativa valenciana.

Los años 70 suponen, pues, el despertar definitivo de la narrativa catalana en territorio valenciano, sobre todo a partir de dos obras de referencia que representan sendas tendencias narrativas:

- Assaig d'aproximació a «Falles folles fetes foc», de Amadeu Fabregat, que gana en 1973 la primera convocatoria del premio Andròmina. Esta obra representa la subversión y abre una nueva etapa en la narrativa valenciana.

- El bou de foc, de Joan Francesc Mira, finalista del premio Josep Pla 1973, que supone una profundización en el modelo de novela tradicional.

Estos títulos de dos autores de la Generación del 70 coinciden en la década con la principal producción de otros novelistas mucho más veteranos de las letras valencianas: Enric Valor (1911), Gonçal Castelló (1912) y Josep Rausell (1926).

V. Simbor y F. Carbó señalan, siguiendo fundamentalmente el modelo de Àlex Broch que hemos citado (algunos títulos coinciden), las siguientes tendencias en la novela catalana del País Valenciano durante la década de los 70:

a) Novelas de la subversión del modelo tradicional o antinovelas, que replantean el propio concepto de novela, destinadas a un público minoritario:

- Assaig d'aproximació..., de Amadeu Fabregat.

- Dentadura postissa, de Josep Gandia Cassimiro.

- Espai d' un ritual y Projecte per a destruccions, de Josep Lluís Seguí.

- Coll de serps, de Ferran Cremades.

b) Novelas que profundizan en el modelo tradicional, incorporando nuevas técnicas narrativas y elementos de reflexión sobre el acto creativo:

- Novelas históricas, como Crim de Germania, de Josep Lozano y La regina de la pobla de les fembres pecadrius, de F. Cremades.

- Novelas que recrean el mito de la huida y el retorno, como Rondalla del retorn, de Josep Piera.

- Novelas que ofrecen una gran variedad de historias y discursos: $R a$ mona Rosbif y Mari Catúfols, de Isa Tròlec; El bou de foc, de J. F. Mira; Això diu que era, de Rafael Ferrando y L'anarquista nu, de Lluís Fernàndez.

c) Pervivencia del modelo tradicional (cánones narrativos que recuerdan la novela del siglo XIX), con Enric Valor, que reinicia en 1980, 20 años después de su última novela, la publicación del grueso de su obra narrativa con Sense la terra promesa. 
d) La crónica testimonial, con novelas que surgen tras la desaparición de la censura con el objeto de rescatar del olvido la realidad de la guerra civil y la posguerra:

- La guerra comença ara, de Josep Rausell.

- Sumaríssim d' urgència, de Gonçal Castelló.

En la década siguiente, los años 80 , prácticamente se extingue el modelo novelístico de la subversión, ante la necesidad perentoria de productos asequibles y atractivos para el público en el sólido circuito editorial que tiene a Barcelona como núcleo.

Se produce en esta década, por una parte, un importante desarrollo de la novela histórica en el País Valenciano, con el claro deseo de recuperación de la memoria colectiva y las señas de identidad. Destacan en dicha tendencia autores como Ferran Cremades, Joan M. Monjo, Josep Gregori y Vicent Josep Escartí, los tres últimos pertenecientes a una nueva promoción.

Otra variante de novela de género es la novela erótica, cultivada por autores de promociones anteriores, como Vicent Andrés Estellés (1924), con El coixinet, y Josep-Lluís Seguí (1945), con Diari de bordell. Pero es sin duda la novela negra el género más destacado en territorio valenciano durante la década, convirtiéndose algunos autores en referente para toda la novelística catalana: Ferran Torrent (el principal), Víctor Mansanet, Vicent Marqués o el dúo Rafael ArnalTrinitat Satorre, autores — salvo el segundo- pertenecientes a la Generación de $\operatorname{los} 70$.

En resumen, la narrativa catalana en territorio valenciano, que aparece tardíamente pero de modo contundente (como una traca) en el circuito literario barcelonés, ofrece rasgos peculiares en los 70 - entre otros, la presencia clave de autores de diferentes promociones--, y sigue la dinámica general en los 80 con el predominio de la novela comercial y de género, destacando su protagonismo y aportación incuestionable en el territorio de la novela negra. ${ }^{13}$

\section{ALGUNOS RASGOS DE LA NARRATIVA BALEAR EN CATALÁN}

En general la producción narrativa en las Islas Baleares mantiene las mismas características y periodos del conjunto del territorio de lengua catalana, pudiéndose señalar tan sólo algunos rasgos característicos con respecto a la narrativa peninsular en catalán:

- Tras la guerra civil, se produce en las islas una radical represión y persecución del uso de la lengua catalana, con la consiguiente desarticulación del circuito literario en dicha lengua.

${ }_{13}$ Hemos seguido en este epígrafe las siguientes obras: Ferran Carbó y Vicent Simbor: $L a$ recuperació literària en la postguerra valenciana (1939-1972) y Literatura actual al País Valencià (1973-1992), ambos libros editados en 1993 por el Institut Universitari de Filologia Valenciana. Vicent Salvador y Adolf PIQuer: Vint anys de novel la catalana al País Valencià, Edicions 3 i 4 , Valencia, 1992. 
- La recuperación novelística de la posguerra gira en torno a un nombre, Llorenç Villalonga, referente de jóvenes narradores, cuya obra llega a adquirir una dimensión mítica. Este autor alterna el uso del catalán con el castellano. Su novela más influyente, Bearn o la sala de les nines, se publica en castellano cinco años antes que su edición catalana en 1961.

- La Generación de los 70 supone el auténtico resurgir de la novela en las Baleares, gracias a una abundante nómina de autores que contrasta con el árido panorama de las décadas anteriores: Baltasar Porcel, Antoni Serra, Miquel A. Riera, Josep Melià, Gabriel Tomàs, Antònia Vicens, G. Janer Manila, M. ${ }^{a}$ Anòonia Oliver, Carme Riera, Pau Janer, Llorenç Capellà. M. Ferrà Martorell, Guillem Frontera, Biel Mesquida, Guillem Cabrer, M. López Crespí, Jaume Santandreu, G. Vidal Oliver, Pere Morey, Sebastià Mesquida, Xesca Ensenyat, Valentí Puig, Antoni Marí, etc.

- Estos narradores reflejan en sus primeras obras los cambios sociológicos y culturales producidos en las islas: Crecimiento de la industria turística, aparición de una burguesía desarraigada, choque generacional, inmigración masiva, crecimiento desorbitado de la ciudad de Palma y de las zonas costeras, destrucción del paisaje, cambios en la moralidad y en las costumbres sexuales, etc. En este contexto, suele ser una constante la rebeldía producida por el choque entre los ideales de los jóvenes y el materialismo de la sociedad mallorquina.

- A los planteamientos citados en el epígrafe anterior debe añadirse la influencia del realismo mágico, una corriente de especial incidencia en la narrativa insular, que se debe en parte al éxito alcanzado en ese momento por la literatura hispanoamericana.

- Algunos escritores de la Generación de los 70, desde unas propuestas textualistas y rupturistas, intentan la supresión de los límites entre géneros literarios e incluso entre las diferentes artes, colaborando con los pintores. Tal es el caso de la experiencia titulada Materia de cos, de Steva Terrades y Biel Mesquida, o la novela «collage» de este último, L'adolescent de sal.

- En la mitad de la década de los 80, el panorama literario mallorquín cambia, como sucede en toda la literatura catalana. Son los mismos autores de la promoción anterior, a los que se añaden otros nacidos en la década de los 60 - Jaume Capó, Gabriel Galmés, M. ${ }^{a}$ de la Pau Janer, etc.- quienes, dentro de la heterogeneidad, se caracterizan por su renuncia al experimentalismo y a la actitud de rebeldía individual para volver a temas más universales, con una mayor capacidad de fabulación y el cultivo de la novela de género, en especial la novela negra. El fenómeno tiene que ver con la ampliación del público lector en catalán, gracias al proceso de normalización lingüística, y con la proliferación del mercado editorial que convierte cada vez más la novela en producto comercial. Ambos aspectos son comunes a los tres territorios de la literatura catalana, 
en los que la década de los 80 representa claramente un periodo de uniformidad y de convergencia en el mismo circuito literario. ${ }^{14}$

\section{INFRAESTRUCTURA EDITORIAL: IMPORTANCIA Y EVOLUCIÓN}

Barcelona se había convertido ya en centro de la edición en español durante la segunda mitad del siglo XIX, con sellos como Muntaner, Simon, Gili, Espasa, Seix i Barral y Salvat. Comienza también a desarrollarse en esta capital la edición en catalán a principios del siglo XX, consolidándose en los años 20.

La recuperación de la edición en catalán en la posguerra se inicia con la fundación de la editorial Selecta en 1946 (a partir de la Antigua Catalonia), por Josep M. ${ }^{a}$ Cruzet, aprovechando las concesiones del régimen franquista a la edición en catalán una vez terminada la II Guerra Mundial. En esa década y la siguiente surgen las editoriales Aymà, Dalmau, Barcino, club dels Novel.listes y Albertí en Cataluña, Moll en Mallorca y Lletres Valencianes y L'Espiga en Valencia.

Los años 60 son claves con la aparición de Edicions 62 -fundada por un grupo de activistas catalanistas liderados por Max Cahner y a la que se incorpora en 1964, como director literario, el crítico José M. ${ }^{a}$ Castellet - y la Enciclopèdia Catalana, y el relanzamiento de Proa tras su retorno del exilio en 1964. ${ }^{15}$ También destaca el papel de otras editoriales en catalán, como Nova Terra, Fontanella, D'Estela, Juventut, Alpha, Pòrtic, La Galera y la valenciana Tres i Quatre, todas ellas aparecidas en este periodo, lo mismo que Publicacions de l'Abadia de Montserrat, surgida en torno al monasterio del mismo nombre. ${ }^{16}$

En 1976 nace La Magrana y en 1978 una fundación a fondo perdido del artista A. Tàpies permitirá la creación por parte de tres poetas de la editorial Llibres del Mall (que sucumbe por las deudas a finales de los 80). En 1985, un periodista, un poeta y un diseñador gráfico se unen para crear la editorial Columna, la primera que introduce un estilo agresivo y claramente mercantilista en el campo de la edición en catalán. En esta década de la transición política aparecen también Quaderns Crema, Laertes, Empúries, Eumo, La Campana y Bromera, esta última en Alzira.

Aparte de las editoriales citadas, otras especializadas en castellano se van incorporando también a la edición en catalán, como Ariel, Destino, Bruguera, Alfaguara y Edhasa.

${ }^{14}$ Sobre las características y evolución de la narrativa balear en catalán, puede consultarse el estudio de Pere Roselló Bover, Els moviments literaris contemporanis a les Balears, Conselleria d'Educació y Cultura, Govern de les Illes Balears, en el sitio web http://mnm.es/movlit/

15 Proa había sido fundada en 1928 y, tras exiliarse a partir de la guerra civil, desarrolló su actividad en Perpignan desde 1951.

${ }^{16}$ En 1959, Publicacions de l'Abadia de Montserrat, existente desde el siglo xv, decidió unificar dos publicaciones del monasterio para crear Serra d' Or, que se convertiría en una influyente revista de cultura catalana. A partir de 1971 la editorial inició una etapa importante de publicación de estudios de lengua, cultura y literatura catalanas. 
En los años 90 llega el momento de la concentración en grupos, salvo algunas editoriales independientes que permanecen, como Quaderns Crema: Se constituye el grupo Enciclopèdia (Enciclopèdia Catalana, Proa, La Galera y Pòrtic); nace también el Grupo 62 (Edicions 62, Península, El Aleph, Diagonal), que pasará a manos de La Caixa en 2002; La Magrana se integra en el grupo RBA en 2001 y Columna es adquirida en 1997 por el grupo Planeta, que consigue así introducirse de lleno en la edición en catalán. ${ }^{17}$

Con la concentración empresarial de la edición en catalán se culmina un proceso iniciado en los años 70 . El sector irá pasando de una vocación inicial de servicio e implicación política - proyección de la lengua y la cultura catalanas en el contexto adverso del franquismo- a la profesionalización, el mercantilismo y la competencia - triunfo del criterio empresarial, diversificación y especialización-, una nueva realidad que se instaura en los años 80, con el consiguiente efecto ya citado sobre los derroteros que va a tomar la novela en dicho periodo.

${ }^{17}$ Este proceso de concentración empresarial en el sector, unido al proceso de internacionalización, se produce también de manera irreversible en la edición en castellano, culminando a finales de los 90 con el mercado en manos de tres conglomerados - salvo algunos casos excepcionales, como el de la editorial Anagrama-

- Destaca el caso del grupo Planeta, que controla más del 25\% de la edición de novela en España, incluyendo entre sus sellos editoriales Destino, Planeta, Espasa y Seix Barral, además de Columna Ediciones (libros en catalán), ediciones Martínez Roca, Temas de Hoy, Minotauro, Booket, Ariel y Ediciones del Bronce. Pero ésta es sólo un área del grupo Planeta, que facturó más de 900 millones de euros en el 2001; otras áreas de actividad del grupo son venta directa, audiovisual, coleccionables, enseñanza a distancia, Intemet y medios de comunicación (participaciones en el diario "La Razón», Radio España y la Cadena Cope, entre otras). Finalmente, Planeta ha desarrollado filiales en Argentina, Chile, Colombia, México, Ecuador, Uruguay y Venezuela (con la convocatoria de premios similares al Planeta español en los 4 primeros países).

- También es significativo el caso de la editorial Alfaguara, que pertenece al grupo Santillana, junto con Taurus, Aguilar, Altea, Siruela y Alianza Editorial, además de la cadena de librerías Crisol. A su vez el grupo Santillana (Timón), implantado en toda Sudamérica, USA, Portugal y Reino Unido, pertenece al holding PRISA, el mayor grupo privado de comunicación español - cuyo origen fue precisamente la creación por la familia Polanco de la editorial educativa en 1960-. La impresionante maquinaria mediática de PRISA (Promotora de Informaciones, S.A.) incluye el diario El País y otros pertenecientes al grupo Correo, la Cadena SER y Antena 3 de Radio, la cadena de TV Canal+ y Canalsatélite Digital. El grupo posee además sociedades de producción, distribución y compra de derechos cinematográficos.

- Debemos hacer alusión, en tercer lugar, a la reciente operación llevada a cabo en España por el conglomerado alemán de la comunicación Bertelsmann —creador del Círculo de Lectores y en la actualidad el mayor consorcio mundial de la edición, tras adquirir el grupo americano Random House--, quien, en «joint venture» con el gigante editorial italiano Mondadori (controlado por el holding Fininvest, de Silvio Berlusconi), acaba de crear el Grupo Editorial Randon House Mondadori S. A., que incluye las editoriales adquiridas por ambos socios en nuestro país e Hispanoamérica: Grijalbo, Plaza y Janés, Debate, Sudamericana, Lumen y Galaxia Gutemberg. El grupo posee también una amplia red de filiales en toda Hispanoamérica (que es, como se ve, el nuevo Eldorado de los pujantes grupos editoriales españoles $y$, sin duda, cauce seguro para la completa amortización de sus productos, en un proceso semejante pero inverso al que se produce con el cine americano en Europa). 

talán: ${ }^{18}$

Veamos algunos datos significativos sobre la evolución de la edición en ca-

- Pasa de 672 títulos en 1975 a 5.806 en 1992, el 11,5\% de todos los títulos editados en España, frente al 3\% en 1975.

- Anteriormente se había pasado de 183 libros en 1960 a 548 en 1966, muy por debajo todavía de los 865 títulos en catalán editados en 1936.

- De los 5.793 libros editados en catalán en 1995, 1.824 corresponden a enseñanza y educación, 1.110 a generalidades y 1.022 a literatura (el $17,6 \%)$.

- Con respecto al mismo año 1995, el $80 \%$ de los libros en catalán son editados en Cataluña (el $72 \%$ en Barcelona), el $12,1 \%$ en la Comunidad Valenciana, el 6,5\% en Madrid y el 3,1\% en Baleares.

- En 1993, la venta de las editoriales catalanas en España supuso el $61 \%$ del total. El año anterior, en 1992, Cataluña efectuó el 48,2\% de las exportaciones de libros a nivel nacional.

- En 1995 Cataluña fue la segunda comunidad autónoma en número de ISBNs con 17.442, por detrás de Madrid con 19.485. En Madrid el 95\% de la edición fue privada, frente al $84,5 \%$ en Cataluña.

- En el año 2001 se editaron 7.682 libros en catalán, lo cual representó el $31,3 \%$ de los títulos editados en Cataluña, el $22,4 \%$ de los ejemplares y el $15 \%$ de la facturación total.

- De estos títulos en catalán, el $26,5 \%$ corresponden a libros de texto no universitarios, el $24,6 \%$ están dentro del apartado infantil/juvenil y el $22,8 \%$ son obras literarias.

La edición en catalán está subvencionada por el Departament de Cultura de la Generalitat a través del «suport genèric», creado en diciembre de 2004 por el Conseller de Cultura Max Cahner (quien fuera socio fundador de Ediciones 62 ). A través de esta medida, el departamento de Cultura adquiere, con un $50 \%$ de descuento, entre 300 y 150 ejemplares del libro editado, cantidad que varía en función de su precio. En el año 2002, un total de 1.428 libros se acogieron a dicha ayuda.

${ }^{18}$ Las fuentes sobre la edición en catalán consultadas, tanto para las estadísticas que siguen como para los datos históricos anteriores, son las siguientes: a) Catalunya en clave Gutenberg, conferencia pronunciada por Vicenç Llorca, en representación de la Generalitat de Catalunya, en la Hispanic Division de la Library of Congress, el 23 de abril de 1997, festividad de Sant Jordi, en www.sola-sole.com/llorca.htm b) Informe sobre la política lingüistica 2002, VIII: El llibre i la producció literària en català, Direcció General de Política Linguística de la Generalitat de Catalunya, en http://cultura.gencat.net/llengcat/informe/catala/cap08_02.pdf c) Javier Moret, Tiempo de editores. Historia de la edición en España 1939-1975. Destino, Barcelona, 2002, pp. 347-358. d) Sergio Vila-Sanjuán, Pasando página. Autores y editores en la España democrática, Destino, Barcelona, 2003, pp. 255-274. 
Otras ayudas y subvenciones de la Generalitat a la edición, son las siguientes:

- Ayudas de la Institució de les Lletres Catalanes a personas físicas y entidades privadas sin ánimo de lucro para actividades literarias.

- Ayudas de la Institució de les Lletres Catalanes a empresas editoriales para la traducción de obras al catalán.

- Ediciones en lengua catalana o aranesa de especial interés cultural.

- Edición y difusión de libros de texto y manuales universitarios.

- Convocatoria del Institut Català d'Indústries Culturals de aportaciones reintegrables a proyectos.

- Ayudas del COPEC (Consorci Català de Promoció Exterior de la Cultura) a entidades para la promoción de la cultura catalana en el extranjero.

\section{LOS PREMIOS LITERARIOS: MÁS RECLAMO EDITORIAL QUE PROMOCIÓN INSTITUCIONAL ${ }^{19}$}

Por su abundancia y tradición, los premios literarios deben tenerse en cuenta como factor clave en el desarrollo de la narrativa catalana, factor que con frecuencia va unido al todopoderoso circuito editorial. De hecho, gran parte de estos premios son concedidos por las editoriales, casi siempre en concepto (adelanto) de derechos de autor. Otro aspecto relacionado es la creación de la mayoría de estos premios en los años 80 y 90 , paralelamente al proceso de mercantilización de la novela y su dependencia de un mercado cada vez más competitivo.

Destaca por su prestigio el premio Sant Jordi de novela (1960), que conceden Omnium cultural y la Fundació Enciclopèdia Catalana, pero lo superan económicamente el premio Ramon Llull de prosa (1981), de la editorial Planeta, cuya dotación es de 60.100 euros y el premio de novela Mallorca, creado en 2004 por el Consell de Mallorca, con una dotación de 70.000 euros. ${ }^{20}$

La editorial Columna, perteneciente al grupo Planeta, ofrece los siguientes premios:

- 23 d'abril de narrativa (2002), dotado con 30.000 euros.

- Carlemany de novela - junto con el Govern d'Andorra, Proa y la Fund. Enciclopèdia Catalana- (1994), dotado con 36.000 euros.

- Columna de novela (2001), dotado con 9.000 euros.

${ }^{14}$ Pueden consultarse la lista y el palmarés de los premios, convocatorias, etc., en la base de datos del Departament de Cultura de la Generalitat http://cultura.gencat.es/prelit

${ }^{20}$ Con ser importantes estas cifras, todavía quedan lejos de los principales premios de narrativa en castellano:

- Premio Planeta de novela: 601.000 euros.

- Premio Primavera de novela (Espasa y El Corte Inglés): 200.000 euros.

- Premio Alfaguara de novela: 175.000 dólares.

- Premio Fundación José Manuel Lara (versión madrileña del Planeta): 150.000 euros. 
- Primera Columna de narrativa (2002), dotado con 12.000 euros.

- Nestor Luján de novela histórica (1997), dotado con 6.000 euros.

- Joaquim Ruyra de narrativa juvenil - junto con la Fund. Enciclopèdia Catalana y La Galera - (1963), dotado con 6.000 euros.

Además de los tres citados en colaboración, la Fundació Enciclopèdia Catalana otorga los premios Josep Maria Folch i Torres de narrativa (1964) y Mercè Rodoreda de narrativa - junto con Omnium Cultural- (creado en 1953 con el nombre de Víctor Català, se llama así desde 1997), entre otros.

En territorio valenciano, destaca el premio Octubre de narrativa - premio Andròmina- (1973), de la editorial Tres i Quatre, y los Premis Literaris Ciutat d'Alzira, que otorgan la editorial Bromera y el Ayuntamiento de esa localidad: Ciutat d'Alzira de novela (1989), Bancaixa de narrativa juvenil (1996) y Vicent Silvestre de narrativa infantil (1996), además del premio Enric Valor de Narrativa (1995), promovido por Edic. Bromera y la Diputación de Alicante. Por otra parte, el Ayuntamiento de Gandía ofrece el premio Joanot Martorell de novela (1979) y la Mancomunidad de Municipios de la Safor los premios Enric Valor de narrativa juvenil (1981) y Carmesina de narrativa infantil (1990).

En las Islas Baleares destaca el premio Llorenç Villalonga de novela (creado en 1958 como premio Ciutat de Palma, cambia de nombre en 1994), que concede el ayuntamiento de Palma de Mallorca.

Otros premios concedidos por editoriales en Cataluña son: Documenta de narrativa (1980), de la librería homónima y la editorial Empúries; premios Edebé de literatura infantil y juvenil (1993); premios Gran Angular de narrativa (1990) y El Vaixell de Vapor de narrativa infantil (1984), concedidos por la Edit. Cruïlla y la Fund. Santa María; y el prestigioso premio Josep Pla de prosa (1968), de la editorial Destino.

Entre los numerosos premios concedidos por los ayuntamientos - asociados normalmente con editoriales u otras instituciones- podemos destacar el Lola Anglada de cuentos (1984), el del Ayuntamiento de Terrassa, el Mercè Llimona de cuentos (1998), del Ayto. de Vilanova i la Geltrú, el Pere Quart de humor y sátira (1987), del Ayto. de Sabadell y el Pin i Soler de narrativa (1984), del Ayto. de Tarragona.

Por último, deben citarse dos premios destacados para completar la enumeración, que no pretende tampoco ser exhaustiva: el Prudenci Bertrana de novela (1968), concedido por la fundación de Gerona que lleva su nombre, y el Sant Joan de narrativa (1981), de la Fundación Caixa de Sabadell.

Pero al lado de la maraña de premios marcados por el factor económico y de comercialización de las obras, existen otros galardones que suponen sobre todo el reconocimiento institucional de un autor o una obra por su valor literario. Destacan en primer lugar dos premios sin dotación económica: el Premio de la crítica «Serra d'Or» a diferentes géneros (1967), que concede la revista del mismo nombre editada por Publicacions de l'Abadia de Montserrat; y el premio Lletra d'Or a la obra de creación más importante del año, creado en 1956 por un grupo de amigos amantes de la literatura. 
Destaca también el Premi d'Honor de les Lletres Catalanes, creado en 1969 por Omnium Cultural para premiar a aquellas personalidades que por su obra literaria y su ejemplaridad hayan contribuido a la vida cultural de los territorios de habla catalana. Y desde 1982 se conceden los Premios Nacionales de Literatura de la Generalitat.

También existe el Premi de la Crítica Catalana (1962), en las variantes de narrativa y poesía, y el Premi de la Crítica dels escriptors valencians (1991), para poesía, ensayo narrativa y teatro. Finalmente, el Gremio de libreros de Barcelona y Cataluña concede desde el año 2000 el premio Libreter, y la Cámara del Libro de Cataluña el premio Trajectòria (1998), coincidiendo con la Semana del libro en català.

Desde 1951 se celebra en Barcelona una noche mágica de los premios literarios en catalán, es la Nit de Santa Llúcia, el 13 de diciembre, en la que actualmente se conceden 13 premios de poesía, narrativa, ensayo y medios de comunicación. Los de narrativa son el Sant Jordi, el Mercè Rodoreda, el Joaquim Ruyra (que otorga la revista RECVLL —-editada en Blanes, Girona- desde 1965) y el Josep Maria Folch i Torres.

Según un estudio realizado en 2001 por Lletra (revista virtual de la Universitat Oberta de Catalunya) y el Departament de Cultura de la Generalitat, ${ }^{21}$ existían en ese momento un total de 1.249 premios, teniendo en cuenta todos los convocados en Cataluña más los convocados en catalán fuera de Cataluña (Comunidad Valenciana y Baleares). De estos premios, 430 eran de narrativa.

Del estudio se desprende que el $90 \%$ de todas las convocatorias son para obras inéditas, que la longevidad media de los premios es de 11 convocatorias, el predominio absoluto de la lengua catalana; y, en el caso de los certámenes de narrativa, el atractivo económico de un pequeño porcentaje de premios, el centralismo ejercido por Barcelona y el protagonismo de algunas editoriales:

- De 1.214 premios, $820(68 \%)$ son en catalán, 236 (19,5\%) en catalán y castellano, $99(8 \%)$ en catalán y otras lenguas del estado, $50(4 \%)$ en castellano y el resto en aranés (2) o aranés y castellano (7).

- Para los 430 premios de narrativa, estos porcentajes son: $67,5 \%$ en catalán, $22 \%$ en catalán y castellano, $4,5 \%$ en catalán y otras lenguas del estado y $5,5 \%$ en castellano.

- En cuanto al importe de dichos premios de narrativa, 61 no tienen dotación económica, 136 ofrecen menos de 600 euros, 128 ofrecen entre 600 y 3.000 euros, 51 entre 3.000 y 6.000 euros, 44 entre 6.000 y 30.000 euros, y existen 10 premios de más de 30.000 euros.

- Con respecto a la distribución territorial, el 50\% de todos los certámenes tiene lugar en la provincia de Barcelona y el $75 \%$ en Cataluña. La Comunidad Valenciana, en segundo lugar, cuenta con el 14\% de los premios.

${ }^{21}$ Puede consultarse dicho estudio en http://www.uoc.edu/lletra/premis/estudi2001/presentacion.htm 
- De los premios concedidos por editoriales, destacan Columna con 18 , Bromera con 14 y Proa con 12 premios.

\section{ANÁLISIS}

La literatura catalana y más concretamente la narrativa, constituye un fenómeno único y llamativo por el proceso que ha seguido tras sufrir una drástica prohibición y censura a raíz de la guerra civil, su pronta recuperación en las circunstancias más adversas y su posterior desarrollo favorecido por los tres factores intervinientes en el proceso o circuito literario: abundancia y calidad de autores, eficiente infraestructura editorial y público lector interesado. Pero el hecho sólo puede entenderse y ser analizado en un contexto más amplio, cultural, sociológico y político: el catalanismo o «la catalanidad», esa identidad aglutinante en torno a una lengua común que, además, se sustenta sobre una base económica firme y destacada, un polo de referencia dentro del conjunto del Estado español.

Tras la muerte de Franco y la aprobación de la Constitución de 1978, la transición política española culmina con la aprobación de los Estatutos de Autonomía y la normalización lingüística en los tres territorios de habla catalana, entre 1980 y 1986. La incorporación del catalán a la enseñanza supuso el punto de no retorno en la recuperación lingüística y literaria; su uso en los medios de comunicación, la confirmación de una realidad incuestionable: la etapa de prohibición no había conseguido impedir que el $80 \%$ de la población de las tres comunidades autónomas hablase catalán, una lengua que, con cerca de 10 millones de usuarios en sus diferentes territorios, ocupa un lugar destacado entre las lenguas de la Unión Europea.

Existe en este proceso un factor que debe tenerse en cuenta como decisivo: la conciencia reivindicativa tanto ciudadana como institucional, algo común a las otras autonomías o «nacionalidades» del Estado español con lengua propia. Y ahí están las editoriales «históricas» en catalán que hemos citado, algunas de ellas clandestinas y hasta en el exilio cuando las circunstancias eran adversas. En cuanto a instituciones dedicadas a la recuperación y el desarrollo de la lengua y la cultura, destacan Omnium Cultural, la Fundació Llull, la Asociación de escritores en Lengua Catalana, la Fundació Enciclopèdia Catalana, el Institut d'Estudis Catalans, la Institució de les Lletres Catalanes, etc. Un esfuerzo institucional permanente que conlleva el consiguiente coste económico y cuyas connotaciones políticas son evidentes.

Este último aspecto ha condicionado sin duda alguna la narrativa catalana de las últimas décadas, ya que se aprecia una especie de estigma permanente de inconsistencia, de falta de autonomía, de difícil equilibrio entre lo marginal, lo heroico-testimonial y lo puramente literario. Puede que también subsista cierto complejo de inferioridad con respecto a la narrativa en castellano y la consiguiente línea divisoria cruzada sólo por autores que, ajenos a «la causa», han optado por esta lengua como un valor seguro, algunos de ellos figuras clave de la narrativa reciente: Vázquez Montalbán, Eduardo Mendoza, Juan José Millás, 
Vila-Matas, Félix de Azúa, Rafael Chirbes, Terenci Moix (escribe en ambas lenguas), Ana M. ${ }^{a}$ Moix, Javier García Sánchez, Esther Tusquets y Cristina Fernández Cubas, entre otros.

Desde un punto de vista literario, la evolución de la narrativa catalana en estas décadas no es diferente de la que se ha producido en la narrativa en castellano a partir de los 60, tras superar el lastre de la posguerra y del realismo social. En ambos casos puede hablarse de una «nueva novela» o «nueva narrativa», tanto en el sentido de resurgimiento como de renovación del género.

La crítica ha diferenciado, con Àlex Broch, dos tendencias en esta nueva novela catalana, una renovadora del modelo tradicional y otra transgresora del modelo; también ha señalado Broch ciertas constantes o núcleos temáticos para esa promoción de autores tan importante - literaria y sociológicamente- llamada «Generación de los 70», que nos parecen interesantes porque definen una novela claramente condicionada por factores sicológicos, socio-políticos y culturales: ${ }^{22}$

- El turismo como nuevo fenómeno social.

- La educación sentimental.

- Huida y retorno: el mito del nord enllà.

- Campo y ciudad en la sociedad valenciana.

- La novela política o la oposición al sistema.

- El mito de la destrucción social.

- La mujer como personaje.

- El fin de la progresía o la novela del desencanto.

Desde un punto de vista económico y comercial, la historia de la narrativa catalana en este periodo es la historia del entramado editorial y de los premios literarios - lo cual implica frecuentemente la existencia de círculos y grupos de presión movidos por intereses no estrictamente literarios-. Igual que sucedió en la literatura española, la transición política y la libertad de expresión no aportaron una esperada avalancha de grandes obras que dieran cauce al genio y la libertad creadora tanto tiempo reprimidos. Más bien las aguas fueron adaptándose rápidamente a unos cauces que el mercado editorial, en particular, y el neoliberalismo sin complejos - signo de los nuevos tiempos-en general, habían diseñado. En los años 80 la novela se convirtió en producto, brillando con luz propia la sólida infraestructura editorial de Barcelona, que había pasado del planteamiento ideológico y testimonial al del beneficio y la competitividad en un contexto de permanente modernización. Y el insaciable mercado editorial ha engullido, cual monstruo de varias cabezas, la obra tanto de autores históricos como de figuras consagradas y noveles, que ven al fin abierto el camino de la profesionalización.

Puede que todo sea una especie de espejismo de esta dinámica social, económica y cultural posmoderna, marcada por la globalización y la ley del beneficio a escala. Se fabrica la novela fácil y de impacto para el lanzamiento en las

22 ÀLeX BRoCH: Literatura catalana dels anys v'uitanta, op. cit., p. 59. 
grandes plataformas editoriales, similar al lanzamiento de un éxito cinematográfico en las plataformas de TV digital. También existe el mercado de «novelas-telefilm», de género, para las redes de librerías en supermercados, aeropuertos y otros lugares de público masivo, etc. Pero el proceso desenfrenado produce vértigo y es una trampa en sí mismo porque la lengua catalana no puede competir con el castellano y sus 400 millones de clientela potencial, pero, a su vez, los best-sellers en castellano resultan casi insignificantes al lado de los super-lanzamientos planetarios de los conglomerados editoriales multinacionales. Por otra parte, la industria editorial en su conjunto ve llegada la hora de hacer frente a otros medios digitales o productos multimedia que podrían, a largo plazo, dejarla obsoleta y fuera de rentabilidad (industria del videojuego, libro digital, literatura interactiva en la red, telefonía móvil de última generación como soporte de máxima ubicuidad, etc.), en una sociedad que avanza imparable por la senda de la tecnología digital y que ya ha superado la era de Gutenberg (es decir, del soporte analógico impreso).

En este nuevo contexto, los problemas de la literatura catalana, de la narrativa, seguirán siendo peculiares, con otros condicionantes, con otras y con las mismas limitaciones. Pero será difícil que podamos asistir a otro resurgir tan espectacular como el que hemos descrito en este trabajo. Tendría que ser, en todo caso, tras otro largo periodo de involución y clandestinidad como el surgido tras la Guerra civil de 1936, algo impensable tras la cota de consolidación y calidad que ha alcanzado la literatura catalana actual.

Quedan, sin embargo, importantes cuestiones de fondo que requerirían otros estudios específicos al hilo de la información aportada en este trabajo. $\mathrm{Pa}$ rece clara la repercusión del proceso normalizador para la narrativa catalana de las últimas décadas, así como la «esclavitud» contradictoria que implican las constantes subvenciones, premios y apoyos oficiales a la producción literaria. Se hace necesaria una especie de superación dialéctica de esa tensión entre ideología y mercado, entre literatura y política, en aras de un nuevo equilibrio que favorezca la consolidación y el crecimiento, acorde con los tiempos que corren, del sin duda magnífico potencial de la literatura - la narrativa - catalana.

¿Cómo y hasta qué punto se ha producido la normalización lingüística en cada territorio? ¿Cuáles han sido exactamente las consecuencias para la normalización literaria? ¿Compensan los pros a los contras de una literatura subvencionada? ¿Tiene algo que ver la situación actual con la frescura y la autenticidad del resurgir literario y cultural catalán de los años 30 ?

Son preguntas que este trabajo sólo acierta a formular, que tal vez se desprenden de nuestro recorrido objetivo y concreto por un periodo y un género de una de las literaturas que conforman el panorama plurilingüe y pluricultural del Estado español. Cedemos la palabra, para terminar, a Enric Sòria, ${ }^{23}$ cuya crítica tal vez ayude a aclarar las cuestiones planteadas:

${ }^{23}$ ENRIC SòRIA: «Ser i esdevenir: dos debats recurrents per a la fi d'un mil-lenni», en Literatura catalana contemporània, Glòria Bordons y Jaume Subirana (eds.), Universitat Oberta de Catalunya, Barcelona, 1999, pp. 383-384. 
Progressivament, doncs, el de la normalització esdevingué un rètol emmascarador d'una realitat frustrant (per als qui l'empraven) en comptes de la definició clara d'un propòsit més o menys discutible i factible. Com a succedani d'un procés de reconstrucció nacional, l'esforç normalitzador ha intentat la modernització d'una literatura excessivament tendent a la carrincloneria, la desconnexió amb l'exterior i l'ostensible negativa a tenir en compte els fenòmens culturals de masses. Ha pretès, doncs, fer de la catalana una literatura comparable a les que fabriquen els estats nació normals. Per un altre costat, ha afegit una pesada càrrega ideològica a aquest esforç. Ha tractat la cultura com si no fos una realitat multiforme, sinó un símbol polític. La ideologia normalitzadora ha tendit a burocratitzar i corsecar l'expressió escrita de la cultura a Catalunya i l'ha feta passar per penosos llits de Procust. Alhora, ha tendit a potenciar tota mena de succedanis dels productes literaris per imitar; succedanis que eren venuts com a normals i homologables en peu d'igualtat amb els models estrangers. En resum, la ideologia normalitzadora ha obert les fronteres genèriques $i$ expressives de la literatura catalana i alhora ha contribuit molt poderosament a confondre els objectius estètics (culturals) i els nacionals (polítics), a sancionar subproductes i a estendre dins el món literari català el mimetisme superficial i la mediocritat autocomplaguda, a més de convertir l'esperit crític poc menys que en un crim de lesa pàtria.

Les òbvies implicacions ideològiques de l'etiqueta normalitzadora han suscitat una crítica tan aguda com immisericorde per part d'alguns intel-lectuals. Per això, al llarg dels anys noranta ha caigut en desuetud. Això no vol dir que el debat que vehiculava (i que confonia), el que pretén aclarir cap on va la literatura catalana, s'haja extingit. Els debats actuals passen, d'una banda, per la incorporació de nous mitjans tecnològics i l'ampliació, encara no acomplerta, de límits temàtics, ideològics i expressius en la nostră llengua. De l'altra, passen per una avaluació lúcida de les possibilitats d'una literatura en aquesta llengua, per ser veu efectiva, en la varietat i també en la profunditat, d'aquestes societats. Una avaluació que exigeix l'abandonament de la síndrome de malalt perpetu o de cultura protegida, en constant demanda d'ajuts a les institucions, però que també ha de perdre els deliris de grandesa que han confós la normalitat literària i cultural amb una impossible ubiqüitat del nostre verb.

\section{BIBLIOGRAFÍA Y FUENTES UTILIZADAS}

\section{Libros}

Bordons, G. y SubiRANA, J. (eds.): Literatura catalana contemporània, Universitat Oberta de Catalunya, Barcelona, 1999.

Broch, A. y otros: 70-80-90-Literatura (Dues dècades des de la tercera i lultima), Quaderns 3 i 4, València, 1992.

Broch, A. Y otros: Panorama de la Literatura Catalana, Departament de Cultura, Generalitat de Catalunya, Barcelona, 1997.

Broch, A.: Literatura catalana dels anys vuitanta, Ediciones 62, Barcelona, 1991. 
BROCH, A.: Literatura catalana dels anys setanta, Ediciones 62, Barcelona, 1980.

CARBÓ, F. Y SIMBOR, V.: La recuperació literària en la postguerra valenciana (19391972), Institut Universitari de Filologia Valenciana, València, 1993.

Carbó, F. y Simbor, V.: Literatura actual al País Valencià (1973-1992), Institut Universitari de Filologia Valenciana, València, 1993.

Graells, G.-J. y Pi de Cabanyes, O.: La Generació Litèraria dels 70, Pórtico, Barcelona, 1971.

Martínez CACHeRo, J. M.a: La novela española entre 1936 y el fin de siglo, Castalia, Madrid, 1997.

Moret, J.: Tiempo de editores. Historia de la edición en España 1939-1975, Destino, Barcelona, 2002.

Salvador, V. y PIQuer, A.: Vint anys de novel.la catalana al País Valencià, Edicions 3 i 4, València, 1992.

SERRA, F.: La nueva narrativa española. Tiempo de tregua entre ficción e historia, Pliegos, Madrid, 2000.

URquizu SARASUA, P. (ed.): Introducción a las lenguas y literaturas Catalana, Gallega y Vasca, UNED, Aula Abierta, Madrid, 2004.

VIL.A-SANJuán, S.: Pasando página. Autores y editores en la España democrática, Destino, Barcelona, 2003.

\section{Otras publicaciones, estudios e informes}

- Quaderns Divulgatius, n. ${ }^{\circ}$ 6, Associació d'Escriptors en Llengua Catalana, septiembre 1996.

- Insula, n. ${ }^{\circ}$ 589-590, enero-febrero, 1996, monográfico titulado El espejo fragmentado. Narrativa española al filo del milenio.

- LlORCA, V.: Catalunya en clave Gutenberg, conferencia pronunciada, en representación de la Generalitat de Catalunya, en la Hispanic Division de la Library of Congress, el 23 de abril de 1997, en www.sola-sole.com/llorca.htm

- Informe sobre la política lingüística 2002, VIII: El llibre i la producció literària en català, Direcció General de Política Lingüística de la Generalitat de Catalunya, en http://cultura.gencat.net/lengcat/informe/catala/cap08_02.pdf

- Los premios literarios en Cataluña o en catalán en otros territorios, estudio realizado por la Universidad Oberta de Catalunya, en http://www.uoc.edu/letra/premis/estudi2001/presentacion.htm

- Roselló Bover, P., Els moviments literaris contemporanis a les Balears, Conselleria d'Educació y Cultura, Govern de les Illes Balears, en http://mnm.es/movlit/

\section{Sitios web}

http://www.grec.net/home/: Buscador del Grupo Enciclopèdia Catalana.

http://mmlab.ua.es/lletraferit/: Sitio web de la Universidad de Alicante sobre Literatura valenciana actual. 
http://www.uoc.edu/lletra/: Lletra, revista de literatura catalana en la red.

http://www.uoc.edu/lletra/noms.html: enlace de la página anterior con una base de datos de autores y obras.

http://cultura.gencat.net/: Departamento de Cultura de la Generalitat.

http://cultura.gencat.net/prelit: Enlace con una base de datos de premios literarios, del Departamento de Cultura de la Generalitat.

http://cultura.gencat.net/ilc/qeq/: Enlace de la página de la Generalitat que contiene una base de datos de autores y obras.

http://www.escriptors.com/: Asociación de Escritores en Lengua Catalana (AELC). 